\title{
Editorial for special issue
}

Introduction to the special issue: Air quality on the South African Highveld

\author{
Elizabeth Masekoameng ${ }^{1}$, Gerrit Kornelius $\mathbb{1}^{2}$ and Sean 0'Beirne ${ }^{3}$ \\ ${ }^{1}$ Gordon Institute of Business Science, University of Pretoria \\ ${ }^{2}$ Department of Chemical Engineering, University of Pretoria \\ ${ }^{3}$ SE Solutions (Pty) Ltd, Postnet Suite 52, Centurion, 0046
}

https://doi.org/10.17159/caj/2020/31/2.12877

The eastern Highveld of South Africa creates the 'perfect storm' for poor air quality. A variety of surface and elevated sources of air pollution emit into an atmosphere with frequent unfavourable conditions for the dispersion of the pollutants. Such conditions are especially dominant in winter.

Atmospheric emissions derive from eleven very large coal fired power stations, each accompanied by large scale ash disposal sites, that form the backbone of the country's energy supply. Feeding the power stations are multiple open cast coal mines with drilling, blasting, coal and waste rock transport, crushing facilities and long unpaved haul roads. In addition to supplying the power stations, coal mines surround and supply the Sasol operation at Secunda, which is a large coal gasification, synthetic fuel production and wide-range hydrocarbon based chemical manufacturing operation. More than 140 million tonnes of coal are mined each year to supply the two key energy hubs of electrical power and liquid fuels.

Abandoned mines (some which are burning underground) discard and waste coal dumps that are prone to spontaneous combustion and sources of wind-blown dust scar the landscape. The area is also home to ferrochrome smelters and other large industrial processes near Emalahleni and Middelburg.

Air quality in the Highveld is also affected by veld fires. In summer, the entire Highveld area is green. This greenery is either large cattle pastures, seemingly endless expanses of maize and other crops and ever decreasing outcrops of natural vegetation. In winter however, the area transforms into a dry brown and khaki landscape with frequent fires that extend over large areas, transforming the once green vegetation into hundreds of tonnes of ash and semi-volatile hydrocarbons that are emitted to atmosphere.

Some 15 million people live in this area too. From individual farmsteads, through the many small towns, the larger urban centers and finally, but perhaps most importantly, the lowincome, dense settlements. Multiple informal settlements append to these larger dense settlements or exist as islands with very limited services. Unemployment is rife and so is poverty in these areas with high levels of crime. The generally poor socioeconomic circumstances mean that even where electricity connections are available, domestic fuels such as low-quality coal, wood and litter are widely used in rudimentary appliances for cooking, space heating and hot water. In addition, the virtual absence of domestic waste collection services compels continual burning of such waste, often in close proximity to dwellings.

Above this highly complex array of land uses and socio-economic circumstances is the Highveld atmosphere. The quintessential feature of this atmosphere is its stability. The large continental anti-cyclone creates a highly stable atmosphere in both summer and winter, but it is in the winter that the stability really comes to the fore. The same anticyclone that drives that stability also prevents the inward flow of maritime moist air, making winters bone dry and removing all obstacles to the escape of heat from the surface to space. Diurnal temperature profiles see moderate temperatures in the middle of the day, but as the sun starts to dip, the temperatures drop reaching their lowest point just before dawn the following day and then recovering again as the sun rises. The cycle is repeated daily.

Strong, deep surface inversions are an almost everyday occurrence in the Highveld atmosphere and above that are elevated inversions too. Layers of highly stable air stack one above the other, each preventing the movement of air. A winter's night in the Highveld sees pollution trapped below the inversions become progressively more concentrated resulting in alarming deteriorations in air quality, especially in respect of PM but also $\mathrm{NO}_{2}$ and periodically $\mathrm{SO}_{2}$. Compliance with the NAAQS is unacceptably infrequent.

Unsurprisingly, the people who live in that air show that they do through the manifestation of abnormally high occurrences of upper respiratory tract diseases including asthma attacks. It has been shown (inter alia by the seminal publication referred to in the next paragraph) that it is the children that suffer the worst of the effects. It is a veritable tragedy that the situation has remained largely unchanged for several decades, despite several efforts by government to manage air quality. The most important of these was the development of an air quality management plan for the Highveld Priority Area (DEA, 2012). The plan outlines measures that should be implemented by government, industry, and NGOs to improve air quality in the Priority Area. 
It has been over 8 years since the plan was developed and implemented but there is no significant improvement in ambient air quality. Is the lack of improvement simply imperfect implementation of those interventions or is it due to an inadequate characterization of the multiple emission sources and/or the atmospheric dispersion processes that drive air quality, meaning that the management interventions are not up to the task?

In 1987 Professor Peter Tyson, Dr Fred Kruger and Dr Wynand Louw published what was to become a seminal assessment of the air quality in this region (Tyson, Kruger and Louw, 1987). Since that time there have been many additional investigations including a status quo assessment for the air quality management plan described above. Perhaps most importantly, the network of monitoring stations established in the early 2000s, provides a growing database of continuous ambient air quality monitoring under a wide range of meteorological conditions, spanning more than a decade.

This call for papers sought to consolidate the most recent air quality research undertaken in the Highveld to build on the foundation established by Tyson, Kruger and Louw (1987). Our hope is that through consolidating the investigations, assessments, and ambient air quality monitoring, that management interventions can be refined, improved, and more effectively implemented, with the effect of materially reducing the prevailing disease burden and ultimately giving effect to the constitutional right of people living on the Highveld, to an environment that is not harmful to their health or welfare.

\section{References}

Tyson, P.D., Kruger, F.J. and Louw, C.W. (eds), 1988: Atmospheric Pollution and its Implications in the Eastern Transvaal Highveld, South African National Scientific Programmes Report No. 150, Council for Scientific and Industrial Research, Pretoria 